\title{
Urgences
}

\section{Victor-Lévy Beaulieu, Steven le hérault, Montréal, Stanké, 1985, 342 p.}

\section{Yves Lacroix}

Numéro 14, août 1986

Corps et jouissances

URI : https://id.erudit.org/iderudit/025269ar

DOI : https://doi.org/10.7202/025269ar

Aller au sommaire du numéro

\section{Éditeur(s)}

Urgences

\section{ISSN}

0226-9554 (imprimé)

1927-3924 (numérique)

Découvrir la revue

\section{Citer ce compte rendu}

Lacroix, Y. (1986). Compte rendu de [Victor-Lévy Beaulieu, Steven le hérault, Montréal, Stanké, 1985, 342 p.] Urgences, (14), 77-79.

https://doi.org/10.7202/025269ar d'utilisation que vous pouvez consulter en ligne.

https://apropos.erudit.org/fr/usagers/politique-dutilisation/ 


\section{Victor-Lévy Beaulieu: Steven le hérault, Montréal, Stanké, 1985, 342 pages.}

1. Je dois à Renald Bérubé un premier intérêt pour le prénom d'un héros qui est le septième dans l'ordre des naissances et suit donc immédiatement son frère Abel. Si la référence à Joyce le prédispose à une passion pour l'écrivain irlandais. le calembour discret qui tire le lexème vers seven apparente le personnage au frère douloureux (appelé ironiquement le Septième) de Jean Le Maigre. dont Marie-Claire Blais a dévoilé le destin quatre ans avant l'épiphanie de la famille Beauchemin. Un deuxième dévoiement apparaît dans l'attribut qui dépouille Steven de sa fonction de héros afin de le mieux blasonner de son rôle d'annonciateur. Ce type de détoumenent égocentrique est une des stratégies principales du roman, depuis le pillage ponctuel et superficiel de la Bible et des Évangiles, de la biographie de Tchéknov, des textes de Ducharme, de Mallarmé. de Melville toujours, jusqu'à l'appropriation par Abel des caractéristiques du frère joycien, son désir pour la mère et pour la soeur la plus caressante. Steven est un modèle blond, à sexe tendre, raillé par Abel. Il réalise avec Gabriella et la complicité de la mère un idéal familial, tendre et serein, animal et incestueux. qui obsède Abel et l'enrage. La sexualité chez ce dernier est exacerbée, outrancière, irréconciliée, motif et objectif de tous les saccages. Scatologique. Hautement morale dans la provocation et le scandale.

Le projet de La saga des Beauchemin est énoncé pour la première fois en 1974. en même temps que celui d'un livre qui s'intitulerait Steven le hérault. Comme tous les romans de VLP, celui-ci devait avoir Abel pour narrateur. Steven en aurait êté le héros. "le hérault de la geste des Beauchemin, une manière d'archange annonçant à tous la venue du Livre définitif, celui de la tribu" (Steven... p. 151). Encore une fois chez VLB, le roman les hypostasie dans sa propre diégèse, cette fois pour y être interdit. Abel ne réussissant pas à composer l'épopée que l'auteur nous promet depuis près de quinze ans. Steven est dépouillé de sa fonction messiannique. dorénavant sujet manipulé d'une quête dont son aîné immédiat demeure à la fois destinateur et destinataire.

2. Steven le hérault reprend le roman familial à la fin de Don Quichotte de la démanche, une fois achevée la longue dénive d'Abel dans l'imaginaire de Melville. Le narrateur est externe et nous rappelie que les histoires antérieures sont des délires plus ou moins hallucinés du personnage écrivain. Steven et Gabriella reviennent de Paris après quinze ans d'absence et la mère vient les accueillir à Mirabel. Elle n' est pas morte comme il a déjà été écrit. C'est Abel qui est responsable de ce mensonge et le père ne pardonne pas cet irrespect. Le récit procède avec un calme et une sérénité auxquels VLB ne nous a pas habitués et nous imaginons que la famille Beauchemin et "le paysage québécois" nous seront livrés avec une nouvelle distanciation. Nous sommes tout de suite détrompés. La focalisation est constamment modifiëe. d'abord par des mimétismes de la narration en fonction du personnage focalisé. De plus, il apparait dès les premières pages que la narration est piquée de courts monologues intérieurs dont les limites ne sont pas marquées, avec des confusions momentanées pendant lesquelles lintériorité du personnage coincide avec celle du narrateur. À ces coincidences des perspectives il faut ajouter les analepses ponctuelles, les fragments d'une histoire qui se serait passée à Paris ou à Trois-Pistoles, rêveries de l'un ou l'autre personnage, images 
fugitives dont la faible pertinence diégétique suggère qu'il s'agit là d'une mémoire à élucider, celle du narrateur, référant par sa gratuité à la biographie de l'auteur.

3. La narration de Steven le hérault apparaît bien sage après les narrateurs et perspectives multiples des romans antérieurs. Le délire coutumier n'est pas pour autant absent du récit; non justifiées par la fièvre d'un narrateur, les figures emblématiques et hyperboliques sont l'apanage des personnages et des événements. Il y a d'abord la dénomination de Mam et de Pa qui désigne à la fois les parents et les grands-parents. Il y a le père qui est fou, agenouillé au pied d'un palmier décoré comme un arbre de Noël, préparé à recevoir le Christ-Jésus en octobre. Il y a l'oncle Phil livré à une invraisemblable ivrognerie de Jos Connaissant. Il y a Abel qui mène avec une dangeureuse droguée une existence dépravée. Sur le petit lit de fer de leur enfance, Steven et Gabriella s'abandonnent à l'amour sous le regard tutélaire de Mam. Les outrances sont ressenties avec d'autant plus de violence qu'elles trompent notre impatience de connaître enfin la normalité des Beauchemin. Nous comprenons même, à partir du cinquième chapitre, que les destins de Steven et de Pa sont manipulés par Abel qui, de son appartement de la rue Notre-Dame puis d'un motel à Drummondville, lieux successifs de sa débauche, convie son frère à la transmission du texte inachevé, son père à l'achèvement d'un rite sacrificiel près du lit défait.

Steven le hérault est une allégorie dans laquelle le mouvement romanesque est remplacé par les arguments de la fable. Un couple d'archanges risque sa sexualité douce entre les nuages vers le paysage québécois, afin d'aarriver là d'où nous sommes partis et connaître ce lieu pour la première fois» (p. 25). lls retrouvent une mère déclarée morte. Ils découvrent l'absence du fils maudit et la déchéance du père. En réalité, ils se trouvent impliqués dans une série de configurations dans lesquelles ils perdent leur autonomie de personnages. Ils forment avec Mam une triade spéculaire, archaïque et virginale, dont la candeur fascine et rebute le trio antagoniste des irréconciliés: $\mathrm{Pa}, \mathrm{Abel}$ et l'Oncle Phil.

4. Le motif de la quête des origines est double: le premier avoué est "le livre de la famille" ( $\mathrm{p}$. 146), pour la réalisation duquel le père refuse sa mémoire; le deuxième est le corps de la mère, abandonné aux caresses du septième enfant. La deuxième finalité est ultime. La première en est l'artifice mais ne peut être réussie sans l'accomplissement de l'autre. L'inaccessibilité de cet objectif est représentée par une série de tableaux analogues qui en hypertrophient l'expression. Le principe grotesque en est le vindicte de $\mathrm{Pa}$ qui empaille les oiseaux noirs de sa folie, accuse Jos de le tromper avec Mam et prépare la venue du fils prodigue. La double quête de l'exilé est illustrée par le désir emblématique de l'oncle Phil pour Beauté-Féroce et Trois-Pistoles. Abel s'embarque dans un train mythique qui devrait l'emmener dans le Bas-du-fleuve. Le voyage est interrompu par "une grosse fille graisseuse" qui se nomme Lison comme la locomotive de La bête humaine. Elle accompagne Abel au motel Le dauphin pour avoir avec lui une sexualité débridée et maternelle, tellement douce que c'est une libération d'être avalé par elle. Nettoyé de toutes les baves, alcools et excréments par une mère fellinienne qui attend de lui un enfant, Abel se travestit en Jésus afin que soit accomplie la folie de $\mathrm{Pa}$, met en place un système meurtrier, ancestral, que le père déclenchera en s'avançant vers lui. 
C'est à une véritable aventure herméneutique que le lecteur est conviê, strictement balisée par les mots mystères et les histoires alternées, programmée par un narrateur qui tient à paraître pour une fois maître de ses moyens, autant que l'est son vicaire Abel, plus inteligent que tout un chacun, lecteur comme personnage.

5. Il y a chez VLB une souffrance qui, à force de cynisme et de bouffonnerie, réussira peut-être à nous rebuter. Il y a de l'agression dans Steven le hérault, quelque chose d'agressif, quelque chose d'agressé, quelque bête blessée dont on masque les blessures pour les mieux désigner. De quel amour blessée. Une haine paranoide. Steven le hérault est un livre contre l'Autre, un autre qui est le lecteur, celui qui rompt la relation spéculaire de l'auteur à son texte, confond le monstre maternel qui doit mourir et une mère qui serait monstrueuse L'autre c'est aussi le père qui refuse d'assister le fils dans sa progression vers ce fantasme maternel, c'est $P$ a qui tient toute la place entre les bras de Mam. c'est Steven entre les mains de Gabriella. Abel reprend à son compte toutes les propositions, il adopte toutes les postures imposées, afin de mieux se trouver dans la direction des origines, avec un sexe nouvellement doux et tendre, à la fois pénétrant la femme et pénétré par elle, jusqu'à la cécité, puis, coupable. convier le père à proprement l'assassiner, provoquer sa mort pour moins la subir. La grande tribu ne sera peut-être jamais écrite.

Mais tout est réversion dans ce texte, dans la sexualité d'Abel, dans son faux manuscrit. le Livre défait, pourquoi pas dans l'assassinat du fils? Y voir l'assassinat de $\mathrm{Pa}$ ? Il nous sera peut-être donné un jour de lire La grande tribu.

Yves Lacroix 